\title{
Human T Cell Responses to Dengue Virus Antigens Proliferative Responses and Interferon Gamma Production
}

\author{
Ichiro Kurane, * Bruce L. Innis, ${ }^{*}$ Ananda Nisalak, ${ }^{\ddagger}$ Charles Hoke, ${ }^{5}$ Suchitra Nimmannitya," \\ Anthony Meager,' and Francis A. Ennis* \\ *Division of Infectious Diseases, Department of Medicine, University of Massachusetts Medical Center, Worcester, Massachusetts \\ 01605; ${ }^{\ddagger}$ Department of Virology, Armed Forces Research Institute of Medical Sciences, Bangkok 10400, Thailand; ${ }^{\S}$ Division of Tropical \\ Virology, Walter Reed Army Institute of Research, Washington, DC 20307; "Children's Hospital, Bangkok 10400, Thailand; and \\ 'Division of Immunobiology, National Institute for Biological Standards and Control, Hertfordshire, EN6 3QG, United Kingdom
}

\section{Abstract}

The severe complications of dengue virus infections, hemorrhagic manifestations and shock, are more commonly observed during secondary dengue virus infections than during primary infections. It has been speculated that these complications are mediated by cross-reactive host-immune responses. We have begun to analyze human $T$ cell responses to dengue antigens in vitro to explain the possible role of $T$ lymphocytes in the pathogenesis of these complications. Dengue antigens induce proliferative responses of PBMC from dengue antibody-positive donors, but do not induce specific proliferative responses of PBMC from dengue antibody-negative donors. IFN $\gamma$ is detected in the culture fluids of dengue-immune PBMC stimulated with dengue antigens. The cells that proliferate in the dengue antigen-stimulated bulk cultures have $\mathrm{CD3}+, \mathrm{CD} 4+$, CD8-, CD16-, and CD20- phenotypes. Dengue-specific T cell lines were established using limiting dilution techniques. They have CD3+, CD4+, and CD8- phenotypes, and produce IFN $\gamma$ in response to dengue antigens. Culture fluids from dengue-immune PBMC stimulated with dengue antigens, which contain IFN $\gamma$, augment dengue virus infection of human monocytes by dengue virus-antibody complexes.

These results indicate that PBMC from dengue-immune donors contain $\mathrm{CD4}+\mathrm{T}$ cells that proliferate and produce IFN $\gamma$ after stimulation with dengue antigens, and suggest that the IFN $\gamma$ that is produced by these stimulated dengue-specific $T$ cells may contribute to the pathogenesis of dengue hemorrhagic fever and dengue shock syndrome by increasing the number of dengue virus-infected monocytes in the presence of cross-reactive anti-dengue antibodies.

\section{Introduction}

The severe complications of dengue virus infections, hemorrhagic manifestations and shock, are much more commonly observed during secondary infections with a heterologous serotype of dengue virus than during primary infections (1). It

Address reprint requests to Dr. Francis A. Ennis, Division of Infectious Diseases, Department of Medicine, University of Massachusetts Medical Center, Worcester, MA 01605. 1988.

Received for publication 11 May 1988 and in revised form $20 \mathrm{July}$

J. Clin. Invest.

(c) The American Society for Clinical Investigation, Inc.

0021-9738/89/02/0506/08 $\$ 2.00$

Volume 83, February 1989, 506-513 has been speculated that dengue hemorrhagic fever (DHF) ${ }^{1}$ and dengue shock syndrome (DSS) may be mediated by crossreactive host-immune responses (2). Halstead et al. have reported that anti-dengue antibodies at subneutralizing concentrations enhance dengue virus infection of Fc receptor-positive cells $(3,4)$. They have hypothesized that the number of dengue virus-infected monocytes increases in secondary infections because of the presence of anti-dengue antibodies and this results in DHF and DSS (1).

We recently reported that IFN $\gamma$ augments dengue virus infection of human monocytes and a human monocytic cell line, U937 (5). This augmentation required the presence of anti-dengue antibody, and the augmentation of infection was significantly correlated with the increased expression of $\mathrm{Fc} \gamma$ receptors induced by IFN $\gamma$. We reported earlier that PBMC from influenza-immune donors produce high titers of IFN $\gamma$ when stimulated with influenza virus in vitro (6). These two observations stimulated us to consider further the role of dengue-specific $T$ cells in the pathogenesis of dengue virus infections. In this paper we describe human $\mathrm{T}$ cell proliferative responses and IFN $\gamma$ production in vitro induced by dengue antigens. PBMC from dengue antibody-positive donors proliferate and produce IFN $\gamma$ after stimulation with dengue antigens. The responding cells are $\mathrm{T}$ cells $(\mathrm{CD} 3+)$ with CD4 (helper/inducer) phenotype. The IFN $\gamma$ produced augments dengue virus infection of human monocytes by dengue virusantibody complexes.

\section{Methods}

Human PBMC. Peripheral blood specimens were obtained from healthy adult Thai Red Cross blood bank donors in Bangkok, Thailand, and from two American donors who were known to have been infected with dengue virus. The sera of these donors contained hemagglutination-inhibiting (HAI) antibodies to dengue viruses (mean HAI titers; $1: 49$ to dengue $1,1: 58$ to dengue $2,1: 118$ to dengue $3,1: 272$ to dengue 4). Most of the Thai people have antibodies to dengue viruses by age 10 (7). The two American donors had previously been immunized with yellow fever vaccine. Both were known to have been infected with dengue 3 virus, strain $\mathrm{CH} 53489$, by virus isolation from blood and they developed antibody responses to dengue virus. PBMC were also obtained from healthy blood bank donors from Massachusetts who did not have detectable levels of antibodies to dengue virus determined using a plaque reduction neutralization test that has been described earlier (8). We define dengue-immune donors as dengue antibody-positive donors, and non-immune donors as dengue anti-

1. Abbreviations used in this paper: DHF, dengue hemorrhagic fever; DSS, dengue shock syndrome; HAI, hemagglutination-inhibiting antibodies; [ $\left.{ }^{3} \mathrm{H}\right] \mathrm{TdR}$, tritiated thymidine; TW20, Tween 20 . 
body-negative donors. PBMC were separated by Ficoll-Hypaque density gradient centrifugation methods (9). Cells were resuspended at the concentration of $1 \times 10^{7} / \mathrm{ml}$ in RPMI 1640 medium containing $10 \%$ FCS (Gibco Laboratories, Grand Island, NY) and 10\% DMSO (Fisher Scientific Co., Springfield, $\mathrm{NJ}$ ) and were cryopreserved until use (8).

Viruses. The dengue virus strains used were type 1, the Hawaii strain; type 2, the New Guinea C strain; type 3, the CH53489 strain, and type 4, the 814669 strain. Dengue virus types 1 and 2 were supplied by Dr. Walter E. Brandt, and type 4 was supplied by Mr. Jack McCown of the Walter Reed Army Institute of Research. Dengue virus type 3 was supplied by one of the authors (Dr. Bruce Innis).

Preparation of dengue antigens. Dengue antigens were prepared using dengue virus-infected Vero cells as previously reported for measles virus (10). Vero cells were infected with dengue virus at an approximate multiplicity of infection of 1 plaque-forming unit/cell, and cultured in MEM containing $2 \%$ FCS. When $50 \%$ of the monolayer developed cytopathic effects, the cells were removed using cell scrapers (Costar Corp., Cambridge, MA), washed three times with PBS at $4^{\circ} \mathrm{C}$, treated with $0.025 \%$ glutaraldehyde (Sigma Chemical Co., St. Louis, MO) in PBS for $15 \mathrm{~min}$ at $4^{\circ} \mathrm{C}$, washed again three times with PBS, and resuspended in RPMI 1640 . They were then sonicated with a sonic dismembrator (Fisher Scientific Co., Pittsburgh, PA), and centrifuged at $2,500 \mathrm{rpm}$ for $10 \mathrm{~min}$. The supernatant fluids were collected and used as dengue antigens. Control antigens were prepared in a similar manner using uninfected Vero cells. $3 \mathrm{ml}$ of antigen were obtained from $1575-\mathrm{cm}^{2}$ flasks (Costar Corp.) of confluent Vero cells. Alternative antigens such as purified dengue virus or mosquito cell (C6/36)-derived dengue antigens did not induce specific proliferative responses.

Induction of proliferative responses of PBMC. $2-4 \times 10^{5}$ PBMC were cultured with dengue antigens diluted at 1:30 in $0.2 \mathrm{ml} \mathrm{RPMI}$ containing 10\% human AB serum (Hazleton Research Products, Inc., Lenexa, KS) and $5 \times 10^{-5} \mathrm{M}$ 2-mercaptoethanol (Sigma Chemical Co.) in 96-well round-bottom plates (Costar, Cambridge, MA) at $37^{\circ} \mathrm{C}$ for 6 days. Cells were pulsed with $1.25 \mu \mathrm{Ci}$ of tritiated thymidine $\left(\left[{ }^{3} \mathrm{H}\right] \mathrm{TdR}\right)$ for $8 \mathrm{~h}$ before harvest. Cells were harvested using a multiharvester (Titertek, Skatron Inc., Sterling, VA) and $\left[{ }^{3} \mathrm{H}\right] \mathrm{TdR}$ incorporation was counted in a liquid scintillation counter (Packard Instrument Co., Sterling, VA).

Maintenance of dengue antigen-stimulated PBMC. Bulk cultures were established using $4 \times 10^{5}$ PBMC cultured with dengue antigens diluted to a final concentration of 1:30 in $0.2 \mathrm{ml} \mathrm{RPMI}$ containing $10 \%$ human $\mathrm{AB}$ serum, which had been obtained from a healthy, dengue antibody-negative blood bank donor at the University of Massachusetts Medical Center, in 96-well round-bottom plates for $7 \mathrm{~d}$. In some experiments, blast cells were enriched on day 7 by Ficoll-Hypaque density gradient centrifugation. $2 \times 10^{5}$ blast cells were cultured with 2 $\times 10^{6} \gamma$-irradiated $(3,000 \mathrm{rad})$ autologous PBMC in $2 \mathrm{ml}$ of medium supplemented with 10\% IL 2 (Cellular Products, Inc., Buffalo, NY) in 24-well flat-bottom plates (Costar Corp.). On day 14, blast cells were enriched again, and restimulated as described above.

Establishment of antigen-specific $T$ cell lines using a limited dilution method. $4 \times 10^{5} \mathrm{PBMC}$ were cultured with dengue 3 antigen at a final concentration of $1: 30$ in $0.2 \mathrm{ml} \mathrm{RPMI}$ containing $10 \%$ human $A B$ serum in 96-well round-bottom plates for $7 \mathrm{~d}$. On day 7 , blast cells were enriched by Ficoll-Hypaque density gradient centrifugation and were cultured at concentrations of 30,10 , and 3 cells/well with $\gamma$-irradiated autologous PBMC $\left(1 \times 10^{5}\right)$ in $0.2 \mathrm{ml}$ RPMI containing $10 \%$ human AB serum (University of Massachusetts Medical Center), 10\% IL 2, and dengue 3 antigen at a final dilution of 1:30 in 96-well round-bottom plates. On day $14,0.1 \mathrm{ml}$ of medium was removed from each well and $0.1 \mathrm{ml}$ of fresh medium with human AB serum, IL 2, and dengue antigen was added to maintain the same final concentrations described above. On day 21 , cells in wells demonstrating growth were transferred to 48-well flat-bottom plates (Costar Corp.) and were further cultured with $1 \times 10^{6} \gamma$-irradiated autologous PBMC in $1 \mathrm{ml}$ of RPMI containing $10 \%$ human $\mathrm{AB}$ serum, $10 \%$ IL 2, and dengue antigen at a dilution of $1: 30$.
Proliferative responses of $T$ cell lines. $1 \times 10^{4} \mathrm{~T}$ cells were cultured with $2 \times 10^{5} \gamma$-irradiated (3,000 rad) autologous PBMC in $0.2 \mathrm{ml}$ RPMI containing $10 \%$ human $\mathrm{AB}$ serum and dengue 3 antigen diluted at 1:30 in 96-well round-bottom plates at $37^{\circ} \mathrm{C}$ for $3 \mathrm{~d}$. Cells were pulsed with $1.25 \mu \mathrm{Ci}\left[{ }^{3} \mathrm{H}\right] \mathrm{TdR}$ for $8 \mathrm{~h}$ before harvest. Cells were harvested using a multiharvester and $\left[{ }^{3} \mathrm{H}\right] \mathrm{TdR}$ incorporation was counted in a liquid scintillation counter.

Phenotypic analysis. Anti-Leu2 (CD8) antibody reacts with suppressor/cytotoxic $T$ cells (11). Anti-Leu3 (CD4) antibody reacts with helper/inducer T cells (11). Anti-Leu4 (CD3) antibody reacts with pan T cells (12). Anti-Leu11 (CD16) antibody reacts with natural killer cells and neutrophils (13). Anti-B1 (CD20) antibody reacts with B cells (14). Anti-Leu2, Leu3, Leu4, and Leu11 antibodies were purchased from Becton-Dickinson \& Co. (Mountain View, CA). Anti-B1 antibody was purchased from Coulter Electronics, Inc. (Hialeah, FL). Cell lines and clones were stained with MAb conjugated with fluoresceinisothiocyanate by direct immunofluorescence methods as described earlier (15). They were observed under a fluorescence microscope (Carl Zeiss, Inc., Oberkochen, FRG).

Immunoassays for IFN. Sandwich-type ELISA for the estimation of IFN activity were developed at the National Institute for Biological Standards and Control of the United Kingdom. For IFN $\gamma$ determination, $50 \mu \mathrm{l}$ of purified rabbit polyclonal antirecombinant human IFN $\gamma$ (16), diluted 1:200 in PBS, was coated on U-bottomed wells of polyvinyl chloride microtiter plates (Dynatech Laboratories, Alexandria, VA) for $2 \mathrm{~h}$ at $37^{\circ} \mathrm{C}$. Remaining sites in wells were blocked overnight with $150 \mu \mathrm{l}$ of $2 \%$ BSA-PBS at $4^{\circ} \mathrm{C}$. Excess antibodies and blocking buffer were removed and wells washed four times with $0.58 \%$ Tween 20 (TW20)-PBS. After the last wash, serial dilutions of human IFN $\gamma$ standard (British Standard 82/587, 3,000 IU per ampoule) or culture fluid samples were added, $50 \mu \mathrm{l}$ per well, and incubated at $37^{\circ} \mathrm{C}$ for $1 \mathrm{~h}$. Wells were then washed four times with TW20-PBS followed by: (a) addition of $50 \mu$ l purified anti-human IFN $\gamma$ MAb, 4SB3 (17) diluted $1: 100$ in $2 \%$ BSA-PBS, and incubation for $1 \mathrm{~h}$ at $37^{\circ} \mathrm{C} ;(b)$ washing with TW20-PBS and addition of $50 \mu \mathrm{l}$ biotinylated sheep anti-mouse immunoglobulin (Amersham International, Amersham, UK), diluted 1:500 in BSA-PBS, and incubation for $1 \mathrm{~h}$ at $37^{\circ} \mathrm{C} ;(c)$ washing with TW20-PBS incubation with $50 \mu \mathrm{l}$ streptavidin-biotinylated horseradish peroxidase complex (Amersham International), diluted 1:500 in $2 \%$ BSA-PBS and incubation for $30 \mathrm{~min}$ at $37^{\circ} \mathrm{C}$; and $(d)$ washing twice with TW20-PBS and twice with $0.1 \mathrm{M}$ citrate-phosphate buffer, pH 5.0, followed by the addition of orthophenylene diamine substrate at $1 \mathrm{mg} / \mathrm{ml}$ in the $0.1 \mathrm{M}$ citrate-phosphate buffer containing $0.006 \%$ hydrogen peroxide. Color was developed in the dark for $30 \mathrm{~min}$ at room temperature and the reaction terminated by addition of $50 \mu \mathrm{l} 1$ $\mathrm{M} \mathrm{H}_{2} \mathrm{SO}_{4}$ to each well. Optical densities were read at $450 \mathrm{~nm}$ in a multiskan (Titertek, Skatron, Inc.). Levels of IFN $\gamma$ in culture fluid samples were interpolated from the IFN $\gamma$ standard calibration curve. The detection limit of the IFN $\gamma$-specific ELISA was $0.5 \mathrm{IU} / \mathrm{ml}$.

For IFN $\alpha$ determination, the ELISA was carried out in a manner similar to that described above for IFN $\gamma$-specific ELISA except that the rabbit and mouse antibodies against IFN $\gamma$ were replaced by IFN $\alpha$-specific antibodies $(18,19)$. This IFN $\alpha$-specific ELISA was calibrated with the first international reference preparation for human leukocyte IFN $69 / 19,5,000$ IU per ampoule, and the detection limit of the assay was $10 \mathrm{IU} / \mathrm{ml}$ in this version.

Effect of IFN produced by PBMC stimulated by dengue antigens on dengue virus infection. Supernatant fluids from cultures of PBMC of dengue-immune donors that had been stimulated with dengue antigen as described above, were diluted to contain $3 \mathrm{U} / \mathrm{ml}$ of IFN $\gamma$, and culture fluids of the same PBMC exposed to control antigen, which did not contain detectable levels of IFN $\gamma$, were diluted similarly. These fluids were then used to pretreat human monocytes for $24 \mathrm{~h}$ before addition of dengue virus-antibody complexes at multiplicity of infection of 10:1. Previous experiments with recombinant human IFN $\gamma$ pretreatment of monocytic cells had demonstrated that these experimental conditions resulted in the production of a low percentage of infected cells $24 \mathrm{~h}$ later in the dengue 2 virus control group (3/212, 
$1.4 \%$ ) and there was no increase in the number of infected cells after pretreatment with IFN $\gamma$; however, there were significant increases in the percentage of infected cells after pretreatment with IFN $\gamma$ and exposure to dengue 2 virus-antibody complexes, $(29 / 207,14 \%$ of cells were infected in the absence of IFN $\gamma$, and 29 and $47 \%$, respectively after pretreatment with 1 or $10 \mathrm{U}$ of IFN $\gamma$.)

Statistical analysis. Differences between values were examined by $t$ test and Chi square test. Differences yielding $P$ values of $<0.05$ were regarded as significant.

\section{Results}

Proliferative responses of PBMC from dengue-immune donors induced by dengue antigens. PBMC from a dengue antibodypositive donor were cultured with dengue or control antigens diluted at various concentrations, and $\left[{ }^{3} \mathrm{H}\right] \mathrm{TdR}$ incorporation was examined. Dengue antigens induced significant proliferative responses of PBMC, and there was a good correlation between the level of the proliferative responses and the concentration of dengue antigens (Fig. 1). Control antigen did not induce significant proliferative responses. A time course study showed that the proliferative responses reached maximum levels on day 6 (data not presented).

The results shown in Fig. 2 illustrate the proliferative responses of PBMC obtained from 11 Thai donors and the 2 American donors who were known to have previously been infected with dengue virus. The PBMC from these donors showed significant proliferative responses induced by dengue antigens ( 8 out of 9 with dengue $1 \mathrm{Ag} ; 10$ out of 13 with dengue $2 \mathrm{Ag} ; 5$ out of 7 with dengue $3 \mathrm{Ag} ; 5$ out of 7 with dengue $4 \mathrm{Ag}$ ). The PBMC from Massachusetts blood bank donors did not significantly proliferate in response to dengue antigens. The failure of PBMC of some Thai donors to respond to certain dengue antigens may be partly because the PBMC were derived from healthy adults, and dengue infections are most common during childhood. Table I contains a summary of the positive proliferative responses induced by dengue antigens using PBMC from Thai and American donors. These results indicate that antigens of the four dengue serotypes can induce proliferative responses using PBMC from dengue antibodypositive donors. Neither dengue antigens nor control antigens induced significant proliferative responses of PBMC from nonimmune donors.

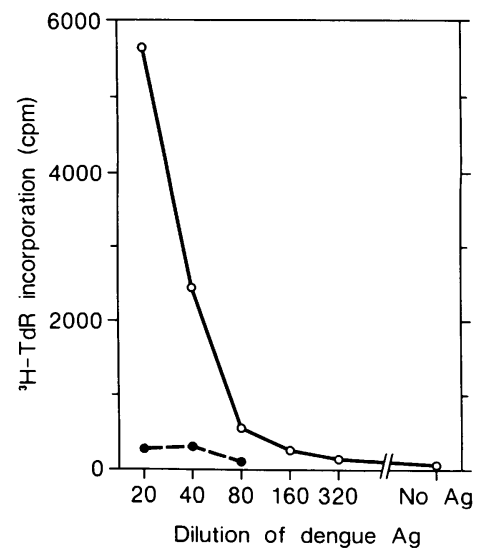

Figure 1. Proliferative responses of dengue-immune PBMC to dengue Ag. 2 $\times 10^{5}$ PBMC from an American donor who had been infected with dengue 3 virus were cultured with dengue $3 \mathrm{Ag}$ or control Vero $\mathrm{Ag}$ at various dilutions for $6 \mathrm{~d}$. Cells were pulsed with $1.25 \mu \mathrm{Ci}^{3} \mathrm{H}$ TdR for $8 \mathrm{~h}$ before being harvested. $\mathrm{O}$, proliferative responses induced by dengue 3 antigen. $\bullet$, proliferative responses induced by control antigen.

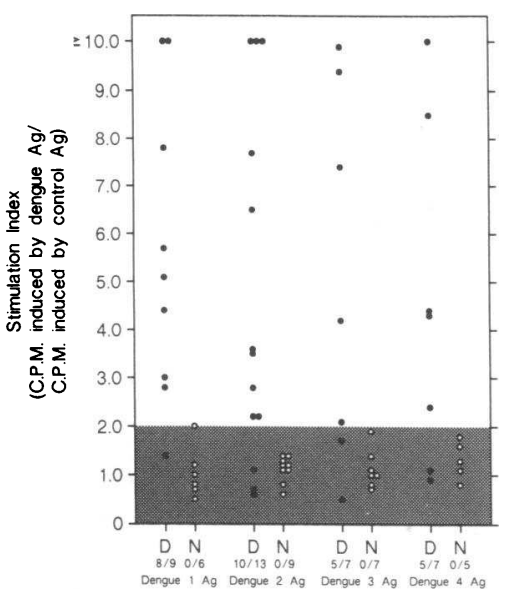

Figure 2. Proliferative responses of PBMC from 11 Thai and 2 American antibody-positive donors. $4 \times 10^{5}$ PBMC were cultured with dengue and control Vero antigens diluted at $1: 30$ for $6 \mathrm{~d}$. Cells were pulsed with $1.25 \mu \mathrm{Ci}\left[{ }^{3} \mathrm{H}\right] \mathrm{TdR}$ for 8 $h$ before harvest. Results were expressed as a stimulation index that was calculated as follows: mean counts per minute induced by dengue $\mathrm{Ag} /$ mean counts per minute induced by control Ag. Stimulation indices $>2$ were considered as positive proliferative responses. $D$, dengue-immune donors. $\mathrm{N}$, nonimmune donors.

Detection of IFN $\mathrm{in}$ the culture fluids of PBMC stimulated with dengue antigens. We examined the culture fluids of PBMC stimulated with dengue antigens for IFN $\gamma$ using ELISA with MAb to human IFN $\alpha$ and $\gamma$. IFN $\gamma$ was detected at high titer in the culture fluids of PBMC from dengue-immune donors stimulated with dengue antigens $(P<0.02$ compared with the amount of IFN $\gamma$-detected in cultures of PBMC from nonimmune donors), but not in the culture fluids of PBMC stimulated with control antigen or cultured alone (Table II). IFN $\alpha$ was not detected in the culture fluid of PBMC after stimulation with dengue or control antigen (data not presented). The culture fluids of PBMC from antibody-negative donors stimulated with dengue antigens did not contain significant titers of IFNs. These results indicate that dengue-immune PBMC produce high titers of IFN $\gamma$ after stimulation with dengue antigens, but do not produce IFN $\alpha$. IFN $\gamma$ was detected at low titers in the culture fluids of PBMC from some donors cultured without antigens. It has been reported that PBMC from some normal adults produce IFN $\gamma$ during in vitro culture without the addition of specific antigens (20).

Characterization of the lymphocytes responding to dengue antigens. We cultured the proliferating lymphocytes with $\gamma$-irradiated autologous PBMC in the presence of dengue antigens and IL 2 for 7 or $14 \mathrm{~d}$, after the original $7 \mathrm{~d}$ of bulk culture stimulation, to characterize the lymphocytes that responded to dengue antigen. Phenotypic analyses showed that the proliferating cells were predominantly $\mathrm{CD} 3+, \mathrm{CD} 4+, \mathrm{CD} 8-$, CD16-, and CD20- (Table III). Therefore, the proliferating cells are $T$ cells with the helper/inducer phenotype. They produced IFN $\gamma$ after stimulation with dengue antigens, but not after stimulation with control antigen (Table IV).

Analysis of responding cells by establishing dengue-specific $T$ cell lines. We further characterized the $T$ cells that respond to dengue antigen by establishing dengue-specific $\mathbf{T}$ cell lines by a limiting dilution method using lymphocytes from one American donor who was known to have been infected with dengue 3 virus. $14 \mathrm{~T}$ cell lines, which responded to dengue 3 antigen but not to control antigen, were established. Three of these lines were further expanded. The JK3 and JK10 lines were established from wells containing 10 blast cells. The JK15 line was established from a well containing 30 blast cells. The 
Table I. A Summary of Proliferative Responses of PBMC from Dengue-immune Donors to Dengue Antigens

\begin{tabular}{|c|c|c|c|c|c|c|}
\hline & \multicolumn{3}{|c|}{ Dengue-immune* } & \multicolumn{3}{|c|}{ Nonimmune } \\
\hline & \multirow[b]{2}{*}{ No. of donors } & \multicolumn{2}{|c|}{$[3 \mathrm{H}] \mathrm{TdR}$ incorporation } & \multirow[b]{2}{*}{ No. of donors } & \multicolumn{2}{|c|}{$\left[{ }^{3} \mathrm{H}\right] \mathrm{TdR}$ incorporation } \\
\hline & & Stimulation index & & & Stimulation index & \\
\hline & & & $c p m$ & & & $c p m$ \\
\hline Dengue 1 & 8 & $\begin{array}{c}7.4 \\
(2.8-15.7)\end{array}$ & $\begin{array}{c}9,011 \\
(1,018-19,343)\end{array}$ & 6 & $\begin{array}{c}1.0 \\
(0.5-2.0)\end{array}$ & $\begin{array}{c}664 \\
(142-2,357)\end{array}$ \\
\hline Dengue 2 & 10 & $\begin{array}{c}7.5 \\
(2.2-19.5)\end{array}$ & $\begin{array}{c}4,644 \\
(1,019-10,872)\end{array}$ & 9 & $\begin{array}{c}1.1 \\
(0.6-1.4)\end{array}$ & $\begin{array}{c}1,038 \\
(93-2,897)\end{array}$ \\
\hline Dengue 3 & 5 & $\begin{array}{c}6.6 \\
(2.1-9.9)\end{array}$ & $\begin{array}{c}6,005 \\
(1,706-13,762)\end{array}$ & 7 & $\begin{array}{c}1.1 \\
(0.7-1.9)\end{array}$ & $\begin{array}{c}732 \\
(158-1,975)\end{array}$ \\
\hline Dengue 4 & 5 & $\begin{array}{c}8.2 \\
(2.4-21.5)\end{array}$ & $\begin{array}{c}7,936 \\
(2,153-17,178)\end{array}$ & 5 & $\begin{array}{c}1.3 \\
(0.8-1.8)\end{array}$ & $\begin{array}{c}611 \\
(185-1,275)\end{array}$ \\
\hline Control Ag & 11 & - & $\begin{array}{c}1,046 \\
(68-4,033)\end{array}$ & 9 & - & $\begin{array}{c}783 \\
(261-2,172)\end{array}$ \\
\hline No $\mathrm{Ag}$ & 11 & - & $\begin{array}{c}630 \\
(69-1,980)\end{array}$ & 9 & - & $\begin{array}{c}529 \\
(95-1,723)\end{array}$ \\
\hline
\end{tabular}

$4 \times 10^{5}$ PBMC were cultured for $6 \mathrm{~d}$ with dengue or control Ag diluted at 1:30. Cells were pulsed with $1.25 \mu \mathrm{Ci}\left[{ }^{3} \mathrm{H}\right] \mathrm{TdR}$ for $8 \mathrm{~h}$ before harvest. Results are presented as averages. * The responses of PBMC of dengue-immune donors who had a stimulation index greater than two with each of the four dengue antigens are included. The stimulation index was calculated from mean counts per minute induced by dengue $\mathrm{Ag} /$ mean counts per minute induced by control Ag. Quadruplicate samples were used.

cloning efficiency was $23 \%$ with 10 cells/well, and $56 \%$ with 30 cells/well, respectively. All three lines had CD3+, CD4+, and CD8 - phenotypes (data not presented), and responded to dengue 3 antigen, but did not respond to control antigen (Table V). They produced IFN $\gamma$ after stimulation with dengue 3 antigen but did not produce IFN $\gamma$ after stimulation with control antigen (Table V). They did not produce significant titers of IFN $\alpha$.

Table II. IFN $\gamma$ Production by PBMC from Dengue AntibodyPositive Donors after Stimulation with Dengue Antigens

\begin{tabular}{|c|c|c|c|c|c|c|}
\hline \multirow[b]{2}{*}{ Donors } & \multicolumn{6}{|c|}{ IFN $\gamma^{*}$} \\
\hline & $\begin{array}{c}\text { Dengue } \\
1 \\
\mathrm{Ag}\end{array}$ & $\begin{array}{c}\text { Dengue } \\
2 \\
\mathrm{Ag}\end{array}$ & $\begin{array}{c}\text { Dengue } \\
\mathbf{3} \\
\mathrm{Ag}\end{array}$ & $\begin{array}{c}\text { Dengue } \\
4 \\
\mathrm{Ag}\end{array}$ & $\begin{array}{c}\text { Control } \\
\mathrm{Ag}\end{array}$ & $\begin{array}{l}\text { No } \\
\text { Ag }\end{array}$ \\
\hline & \multicolumn{6}{|c|}{$U / m l$} \\
\hline \multicolumn{7}{|c|}{ Dengue antibody-positive } \\
\hline $\mathrm{T} 1$ & 25 & 120 & 28 & 70 & 2 & 2 \\
\hline $\mathrm{T} 2$ & 42 & 56 & 51 & 115 & 14 & 14 \\
\hline T3 & 33 & 47 & 14 & 26 & 1 & 3 \\
\hline Al & 32 & 43 & 61 & 38 & 3 & 3 \\
\hline \multicolumn{7}{|c|}{ Dengue antibody-negative } \\
\hline M1 & 8 & 5 & 8 & 5 & 5 & 6 \\
\hline M2 & 3 & 11 & 4 & 3 & 2 & 3 \\
\hline M3 & $<1$ & 2 & 2 & 2 & 2 & 2 \\
\hline M4 & $<1$ & $<1$ & $<1$ & $<1$ & $<1$ & $<1$ \\
\hline
\end{tabular}

$4 \times 10^{5}$ PBMC were cultured for $6 \mathrm{~d}$ with dengue and control $\mathrm{Ag}$ diluted at 1:30. Culture fluids were examined for IFN $\gamma$ by ELISA.

* The titers of IFN $\gamma$ induced by dengue and control antigens were compared by $t$ test between dengue antibody-positive and antibody-negative donors. IFN $\gamma$ induced by dengue $1 \mathrm{Ag}, P<0.001$; by dengue $2 \mathrm{Ag}, P<0.02$; by dengue $3 \mathrm{Ag}, P<0.02$; by dengue $4 \mathrm{Ag}, P<0.01$; by control Ag, $P<0.2$ (not significant); without $\mathrm{Ag}, P>0.2$ (not significant).
Augmentation of dengue virus infection of human monocytes by IFN $\gamma$ produced by $P B M C$ in response to dengue antigen. We tried to determine whether the culture fluids of PBMC stimulated with dengue antigen could augment dengue virus infection of human monocytes. We recently reported that recombinant human IFN $\gamma$ augmented dengue virus infection of human monocytes and monocytic cells in the presence of anti-dengue antibody (5). Culture fluids were obtained from dengue-immune PBMC after stimulation with dengue antigen, and they were then diluted to contain $3 \mathrm{U} / \mathrm{ml}$ of IFN $\gamma$. Culture

Table III. Phenotypes of Short-Term-cultured T Cell Lines Stimulated with Dengue Antigens

\begin{tabular}{lccccccc}
\hline & & \multirow{6}{*}{$\begin{array}{c}\text { Days } \\
\text { of }\end{array}$} & & \multicolumn{5}{c}{ \% positive cells* } \\
\cline { 4 - 8 } Donor & Ag & culture & CD3 & CD4 & CD8 & CD16 & CD20 \\
\hline \multirow{2}{*}{ A1 } & Dengue 3 & 14 & 89 & 84 & 2 & 2 & $<1$ \\
& & 21 & 91 & 83 & 3 & ND & ND \\
T3 & Dengue 2 & 14 & 74 & 46 & 24 & ND & ND \\
T4 & Dengue 2 & 14 & 84 & 80 & 8 & ND & ND
\end{tabular}

$4 \times 10^{5}$ PBMC were cultured with dengue antigens diluted at $1: 30$ in $0.2 \mathrm{ml}$ RPMI 1640 containing $10 \%$ human AB serum in 96-well round-bottom plates for $7 \mathrm{~d}$. On day 7 , blast cells were enriched by Ficoll-Hypaque density gradient centrifugation. $2 \times 10^{5}$ blast cells were cultured with $2 \times 10^{6} \gamma$-irradiated autologous PBMC in $2 \mathrm{ml}$ RPMI 1640 containing 10\% human AB serum, 10\% IL 2 and dengue antigens at a final dilution of 1:30 in 24-well flat-bottom plates for 7 $\mathrm{d}$, and phenotypes were examined. One cell line was restimulated again on day 14 and phenotypes were examined on day 21 .

* MAb used were anti-Leu4 Ab for CD3, anti-Leu3 Ab for CD4, anti-Leu2 Ab for CD8, anti-Leu $11 \mathrm{a}$ Ab for CD16, and anti-B1 Ab for CD20. 
Table IV. Proliferative Responses and IFN $\gamma$ Production by a Short-Term-cultured T Cell Line after Stimulation with Dengue Antigens

\begin{tabular}{|c|c|c|c|c|c|c|c|c|c|}
\hline \multirow{3}{*}{$\begin{array}{l}\text { Culture } \\
\text { days }\end{array}$} & \multicolumn{3}{|c|}{${ }^{3} \mathrm{H}-\mathrm{TdR}$ incorporation } & \multicolumn{6}{|c|}{ IFN } \\
\hline & \multirow[b]{2}{*}{ Dengue Ag } & \multirow[b]{2}{*}{ Control Ag } & \multirow[b]{2}{*}{ No $\mathrm{Ag}$} & \multicolumn{2}{|c|}{ Dengue $\mathrm{Ag}$} & \multicolumn{2}{|c|}{ Control Ag } & \multicolumn{2}{|c|}{ No $A g$} \\
\hline & & & & $\mathrm{IFN} \gamma$ & $\mathrm{IFN} \alpha$ & $\mathrm{IFN} \gamma$ & $\mathrm{IFN} \alpha$ & $\mathrm{IFN} \gamma$ & $\operatorname{IFN} \alpha$ \\
\hline & & $c p m$ & & \multicolumn{6}{|c|}{$U / m l$} \\
\hline 14 & 1,325 & 250 & 270 & 40 & $<10$ & $<1$ & $<10$ & $<1$ & $<10$ \\
\hline 21 & 1,290 & 380 & 432 & 280 & $<10$ & 12 & $<10$ & 10 & $<10$ \\
\hline
\end{tabular}

$5 \times 10^{4}$ short-term-cultured T cells were cultured with $2.5 \times 10^{5} \gamma$-irradiated autologous PBMC in $0.2 \mathrm{ml} \mathrm{RPMI} 1640$ containing dengue $3 \mathrm{Ag}$ or control Ag diluted at 1:30 for $3 \mathrm{~d}$. Cells were pulsed with $1.25 \mu \mathrm{Ci}\left[{ }^{3} \mathrm{H}\right] \mathrm{TdR}$ for $8 \mathrm{~h}$ before harvest. Culture fluids were examined for IFN $\gamma$ and IFN $\alpha$ by ELISA.

fluids of the same dengue-immune PBMC that had been exposed to control antigen were similarly diluted. Human monocytes were exposed to these culture fluids for $24 \mathrm{~h}$. They were then washed and infected with dengue virus-antibody complexes. A similar percent of the monocytes that were cultured without the addition of culture fluids from PBMC and that were treated with the diluted culture fluid from dengue-immune PBMC that had been exposed to control antigen became infected and expressed dengue antigens; however, increased number of the monocytes treated with diluted culture fluids from dengue-immune PBMC that had been exposed to dengue antigen and contained $3 \mathrm{U} / \mathrm{ml}$ of IFN $\gamma$ had dengue viral antigens (Table VI, $P<0.001$ in exp. 1 and $P<0.01$ in exp. 2). This augmenting effect of dengue antigen-stimulated culture fluid was abrogated by anti-IFN $\gamma$ antibody, but not by antiIFN $\alpha$ antibody (data not presented). These results confirmed our previous report that IFN $\gamma$ augments dengue virus infection of human monocytes in the presence of anti-dengue antibody, and suggests that dengue-specific $T$ lymphocytes may have an important role in the pathogenesis of secondary dengue virus infections by increasing the number of dengue virus-infected monocytes via IFN $\gamma$ production.

\section{Discussion}

The role of $\mathrm{T}$ lymphocytes in recovery from dengue virus infections and in the pathogenesis of severe complications has not been explained. In this paper, we demonstrated dengue- specific T lymphocyte proliferative responses with PBMC of dengue antibody-positive humans. We used fixed, sonicated dengue virus-infected Vero cells as antigens, as previously were reported with measles virus (10), because cell-free preparations of live dengue virus did not stimulate PBMC of dengue-immune donors (data not presented). Proliferative responses induced by these antigens are dengue specific, because PBMC of dengue antibody-positive donors respond to dengue antigens but not to control antigen, and PBMC of antibodynegative donors do not respond to dengue or control antigens. Antigens of the four dengue serotypes induced generally similar levels of proliferative responses of PBMC from the Thai adult donors. The dengue infection histories of these adult Thai donors are not known, but they all have high levels of antibodies to the four dengue serotypes, presumably as a result of prior natural infections. The PBMC of an American donor, who had been immunized with yellow fever vaccine and later became infected with dengue 3 virus, responded best to dengue 3 antigen but also responded to dengue 1,2 , and 4 antigens to some degree (data not presented). These results suggest that human $\mathrm{T}$ cell responses to primary dengue infections include both type-specific and serotype cross-reactive responses. Further studies are in progress to determine the subtype specificities of human $\mathrm{T}$ cell responses to dengue infections.

The dengue-specific proliferating lymphocytes are $T$ cells with CD4 phenotype. These results were obtained using bulk culture-stimulated PBMC and dengue-specific $\mathrm{T}$ cell lines. It has been reported that CD4+ $\mathrm{T}$ cells can be divided into two

Table V. Proliferative Responses and IFN Production by Dengue-Specific T Cell Lines after Stimulation with Dengue Antigens

\begin{tabular}{|c|c|c|c|c|c|c|c|c|c|}
\hline \multirow[b]{3}{*}{ Lines } & \multirow{2}{*}{\multicolumn{3}{|c|}{$\left[{ }^{3} \mathrm{H}\right] \mathrm{TdR}$ incorporation }} & \multicolumn{6}{|c|}{ IFN } \\
\hline & & & & \multicolumn{2}{|c|}{ Dengue Ag } & \multicolumn{2}{|c|}{ Control Ag } & \multicolumn{2}{|c|}{ No $\mathrm{Ag}$} \\
\hline & Dengue $\mathrm{Ag}$ & Control Ag & No Ag & $\mathrm{IFN} \gamma$ & $\mathrm{IFN} \alpha$ & $\mathrm{IFN} \gamma$ & $\mathrm{IFN} \alpha$ & $\mathrm{IFN} \gamma$ & $\operatorname{IFN} \alpha$ \\
\hline & \multicolumn{3}{|c|}{ cpm } & \multicolumn{6}{|c|}{$U / m l$} \\
\hline JK3 & 6,185 & 514 & 345 & 70 & 22 & 2 & $<20$ & $<1$ & 21 \\
\hline JK10 & 1,978 & 407 & 275 & 44 & $<20$ & 4 & $<20$ & 2 & $<20$ \\
\hline JK15 & 3,737 & 471 & 206 & 44 & $<20$ & 4 & $<20$ & 3 & $<20$ \\
\hline
\end{tabular}

$1 \times 10^{4}$ cells were cultured with $2 \times 10^{5} \gamma$-irradiated autologous PBMC in $0.2 \mathrm{ml}$ RPMI 1640 containing dengue $3 \mathrm{Ag}$ or control Ag diluted at 1:30 for 3 days. Cells were pulsed with $\left.1.25 \mu \mathrm{Ci} \mathrm{[}{ }^{3} \mathrm{H}\right] \mathrm{TdR}$ for $8 \mathrm{~h}$ before harvest. Culture fluids were examined for IFN $\gamma$ and IFN $\alpha$ by ELISA. 
Table VI. Augmentation of Dengue Virus

Infection of Human Monocytes by IFN $\gamma$ Produced by PBMC in Response to Dengue Antigen

\begin{tabular}{ccc}
\hline & \multicolumn{2}{c}{$\%$ dengue antigen-positive cells } \\
\cline { 2 - 3 } & \multicolumn{1}{c}{ Exp. 1 } & Exp. 2 \\
\hline $\begin{array}{c}\text { Treatment of monocytes* } \\
\text { None (RPMI 1640 containing } \\
10 \% \text { FCS) }\end{array}$ & $22 \%(64 / 286)$ & $5 \%(15 / 274)$ \\
$\begin{array}{c}\text { Diluted culture fluid of PBMC } \\
\text { stimulated with dengue antigen }\end{array}$ & $37 \%(99 / 266)^{\S}$ & $12 \%(38 / 325)^{\pi}$ \\
$\begin{array}{c}\text { Diluted culture fluid of PBMC } \\
\text { stimulated with control antigen }\end{array}$ & $24 \%(75 / 310)^{\|}$ & $5 \%(14 / 301)^{\ddagger}$ \\
\hline
\end{tabular}

The percentage of dengue antigen-positive monocytes pretreated with culture fluids of PBMC stimulated with dengue antigen or control antigen were compared with the percentage of dengue antigenpositive monocytes which was not treated with culture fluid by Chisquare test. ${ }^{\ddagger} P>0.7$ (NS); ${ }^{\circledR} P<0.001 ;{ }^{\prime \prime} P<0.5$ (NS); ${ }^{~} P<0.01$. * Culture fluids obtained from dengue-immune PBMC after stimulation with dengue antigen were diluted to contain $3 \mathrm{U} / \mathrm{ml}$ of IFN $\gamma$, and culture fluids of the same PBMC exposed to control antigen, which did not contain detectable levels of IFN, were diluted similarly. After treatment with these fluids for $24 \mathrm{~h}$, human monocytes were infected with dengue virus or dengue virus-antibody complexes as described in Methods. The percentage of monocytes infected with dengue virus was determined $24 \mathrm{~h}$ after infection by indirect immunofluorescence.

subsets, helper $\mathrm{T}$ cells for antibody production (21) and the inducer of the CD8+ suppressor cells (22). It has also been reported that virus-specific, HLA class II-restricted cytotoxic $T$ cell clones have the CD4 phenotype (23-25). The biological functions of dengue-specific CD4 $+\mathrm{T}$ cells will be analyzed in the future experiments. We are actively pursuing the analysis of dengue-induced $T$ cell responses at the clonal level and have detected dengue specific cytotoxicity (data not presented). Our results, which demonstrate that $\mathrm{CD} 4+\mathrm{T}$ cells respond to dengue-Vero antigen, do not rule out a contribution for CD8+ $\mathrm{T}$ cells during dengue virus infections in vivo. It has been reported that the phenotypes and functions of $T$ cells generated in vitro after stimulation with viral antigens may vary, depending on the form of the viral antigens used to stimulate, in the case of human cytomegalovirus (26) and varicella zoster virus (27). Those reports state that cell-free virus preferentially induces the proliferation of CD4 $+\mathrm{T}$ cells, and that virus-infected autologous fibroblasts stimulated cytotoxic $T$ lymphocytes with a CD8+ phenotype $(26,27)$. We will examine the $T$ cell response at the clonal level, and use autologous cell types as alternative antigen-presenting cells in search for CD8+ responders.

Through the application of these techniques, we hope to define the dengue epitopes which are recognized by human $T$ lymphocytes. Dengue virus has three structural proteins; envelope protein $(\mathrm{E})$, membrane protein $(\mathrm{M})$, and capsid protein (C) $(28,29)$. It also induces seven nonstructural proteins, NS1, NS2a, NS2b, NS3, NS4a, NS4b, and NS5 $(28,30)$. Although the role and immunogenic properties of these 10 proteins has not been defined, $E$ protein is thought to contain epitopes that induce neutralizing antibody responses (31). MAb to E protein protect mice from lethal dengue infection (32). Recently, it has been reported that immunization of mice with dengue 2 virus
NS1 protein provided significant protection against lethal challenge with dengue 2 virus (33). Identification of the epitopes or dengue antigens that are recognized by $T$ cells and may have a role in protection or in the pathogenesis of DHF and DSS is an important area for research.

The severe complications of dengue virus infections, DHF and DSS, are much more commonly observed during secondary dengue infections than during primary infections $(1,2,34)$. However, a small percentage of DHF/DSS cases is observed during primary infections and most of these are primary infections of infants between 6 and 12 mo of age born to dengue antibody-positive mothers $(1,2)$. Kliks et al. recently reported that there is a correlation between the level of maternal dengue antibodies and occurrence of DHF/DSS of the infants during the first year of age (35). Therefore, although we speculate that there is a role for dengue-specific $T$ cells in the pathogenesis of DHF/DSS, which is much more commonly observed during secondary infections, such specific $T$ cell memory responses do not explain these complications when they occur, although much less frequently, during primary infections.

In this paper, we demonstrated that dengue-specific CD4+ $\mathrm{T}$ cells produce high titers of IFN $\gamma$. It has been reported that antigen-specific $\mathrm{T}$ cells produce IFN $\gamma$ after stimulation with viral antigens $(6,36,37)$. The role of IFN $\gamma$ produced by dengue-specific $\mathrm{T}$ lymphocytes is another important subject to be further elucidated. IFN $\gamma$ has potent immunoregulatory functions $(38,39)$. IFN $\gamma$ increases $\mathrm{Fc} \gamma$ receptors on human monocytes $(40,41)$. Human monocytes have been identified as cells that support dengue virus infections (42). It has been reported that anti-dengue antibodies at subneutralizing concentrations augment dengue virus infection of human monocytes, secondary to the increased uptake by monocytes of dengue virus in the form of dengue virus-antibody complexes via Fc receptors (3). We recently reported that recombinant human IFN $\gamma$ augments dengue virus infection of human monocytes and the human monocytic cell line U937 in the presence of anti-dengue antibody, and that the augmented dengue virus infection is due to the augmented expression of Fc receptors induced by IFN (5). In these experiments, we showed that dengue virusspecific CD4+ T cells produce high levels of IFN $\gamma$ in response to dengue antigens and that culture fluids which contain IFN $\gamma$ produced by dengue-specific $T$ cells augment dengue virus infection of human monocytes in the presence of anti-dengue antibody. T cell sensitization and IFN $\gamma$ production would occur during primary dengue infections, and the restimulation of primed cross-reactive T cells, production of IFN $\gamma$ and the presence of virus-antibody complexes in the early phases of secondary dengue infections suggest a model for the pathogenesis of DHF/DSS. Based on these observations, we hypothesize that: IFN $\gamma$ is produced by dengue-specific T lymphocytes after stimulation by dengue virus antigens, and the produced IFN $\gamma$ might contribute to the pathogenesis of DHF and DSS because IFN $\gamma$ increases $\mathrm{Fc} \gamma$ receptors on human monocytes and this increases the number of dengue virus-infected monocytes in the presence of anti-dengue antibodies during secondary dengue infections, and by activating macrophages to release vasoactive compounds.

\section{Acknowledgments}

We thank H. Leung and J. Woolley for excellent technical assistance. This work was supported by grants from the U.S. Army Medical Research and Development Command (DAMD 17-86-C-6208), and 
from the National Institutes of Health (NIH-T32-AI07272). The opinions contained herein are those of the authors and should not be construed as representing the official policies of the Department of Army or the Department of Defense.

\section{References}

1. Halstead, S. B. 1980. Immunological parameters of togavirus disease syndromes. In The Togaviruses: Biology, Structure, Replication. R. W. Schlesinger, editor. Academic Press, Inc., New York. 107-173.

2. Halstead, S. B. 1981. The pathogenesis of dengue: molecular epidemiology in infectious disease. Am. J. Epidemiol. 114:632-648.

3. Halstead, S. B., and E. J. O'Rourke. 1977. Dengue viruses and mononuclear phagocytes. I. Infection enhancement by non-neutralizing antibody. J. Exp. Med. 146:201-217.

4. Halstead, S. B. 1979. In vivo enhancement of dengue virus infection in rhesus monkeys by passively transferred antibody. $J$. Infect. Dis. 140:527-533.

5. Kontny, U., I. Kurane, and F. A. Ennis. 1988. Interferon gamma augments Fc receptor-mediated dengue virus infection of human monocytic cells. J. Virol. 62:3928-3933.

6. Ennis, F. A., and A. Meager. 1981. Immune interferon produced to high levels by antigenic stimulation of human lymphocytes with influenza virus. J. Exp. Med. 154:1279-1289.

7. Sangkawibha, N., S. Rojanasuphot, S. Ahandrik, S. Viriyapongse, S. Jatanasen, V. Salitul, B. Phanthumachinda, and S. B. Halstead. 1984. Risk factors in dengue shock syndrome: a prospective epidemiologic study in Rayong, Thailand. Am. J. Epidemiol. 120:653-669.

8. Kurane, I., D. Hebblewaite, W. E. Brandt, and F. A. Ennis. 1984. Lysis of dengue virus-infected cells by natural cell-mediated cytotoxicity and antibody-dependent cell-mediated cytotoxicity. J. Virol. 52:223-230.

9. Bøyum, A. 1968. Isolation of mononuclear cells and granulocytes from human blood. Scand. J. Clin. Lab. Invest. 21 (Suppl. 97):77-89.

10. Richert, J. R., H. F. McFarland, D. E. McFarlin, A. H. Johnson, J. N. Woody, and R. J. Hartzman. 1985. Measles-specific T cell clones from a twin with multiple sclerosis: genetic restriction studies. $J$. Immunol. 134:1561-1566.

11. Engleman, E. G., C. J. Benike, E. Glickman, and R. L. Evans. 1981. Antibodies to membrane structures that distinguish suppressor/ cytotoxic and helper $\mathrm{T}$ lymphocyte subpopulations block the mixed leukocyte reaction in man. J. Exp. Med. 154:193-198.

12. Ledbetter, J. A., R. L. Evans, M. Lipinski, C. CunninghamRundles, R. A. Good, and L. A. Herzenberg. 1981. Evolutionary conservation of surface molecules that distinguish $\mathrm{T}$ lymphocyte helper/ inducer and $\mathrm{T}$ cytotoxic/suppressor subpopulations in mouse and man. J. Exp. Med. 153:310-323.

13. Lanier, L. L., J. H. Philips, N. L. Warner, and G. F. Babcock. 1984. A human natural killer cell-associated antigen defined by monoclonal antibody anti-Leul1 (NKR-15). Functional analysis and twocolor flow cytometry analysis. J. Leuk. Biol. 35:11-17.

14. Stashenko, P., L. M. Nadler, R. Hardy, and S. F. Schlossman. 1980. Characterization of a human B lymphocyte specific antigen. $J$. Immunol. 125:1678-1685.

15. Kurane, I., D. Hebblewaite, and F. A. Ennis. 1986. Characterization with monoclonal antibodies of human lymphocytes active in natural killing and antibody-dependent cell-mediated cytotoxicity of dengue virus-infected cells. Immunology. 58:429-436.

16. Meager, A. 1987. Antibodies against interferons: Characterization of interferons and immunoassays. In Lymphokines and Interferons: A Practical Approach. M. J. Clemens, A. G. Morris, and A. J. H. Gearing, editors. IRL Press, Oxford, UK. 105-127.
17. Meager, A., S. Parti, S. Barwick, J. Spragg, and K. O'Hagen. 1984. Detection of hybridomas secreting monoclonal antibodies to human gamma interferon using a rapid screening technique and specificity of certain monoclonal antibodies to gamma interferon. J. Interferon Res. 4:619-625.

18. Exley, T., S. Parti, S. Barwick, and A. Meager. 1984. A comparison of the neutralizing properties of monoclonal and polyclonal antibodies to human interferon alpha. J. Gen. Virol. 126:1120-1125.

19. Meager, A., and K. Berg. 1986. Epitope localization of a monoclonal antibody, LO-22 with broad specificity for interferon- $\alpha$ subtypes. J. Interferon Res. 6:729-736.

20. Martinez-Maza, O., U. Andersson, J. Andersson, S. Britton, and M. Deley. 1984. Spontaneous production of interferon-gamma in adult and newborn humans. J. Immunol. 132:251-255.

21. Morimoto, C., N. L. Letvin, A. W. Boyd, M. Hagan, H. M. Brown, M. M. Kornacki, and S. F. Schlossman. 1985. The isolation and characterization of the human helper inducer $\mathrm{T}$ cell subset. $J$. Immunol. 134:3762-3769.

22. Morimoto, C., N. L. Letvin, J. A. Distaso, W. R. Aldrich, and S. F. Schlossman. 1985. The isolation and characterization of the human suppressor inducer T cell subset. J. Immunol. 134:1508-1515.

23. Jacobson, S., J. R. Richert, W. E. Biddison, A. Stainsky, R. J. Hartzman, and H. F. McFarland. 1983. Measles virus-specific T4+ human cytotoxic $\mathrm{T}$ cell clones are restricted by class II HLA antigens. J. Immunol. 133:754-757.

24. Kaplan, D. R., R. Griffith, V. L. Braciale, and T. J. Braciale. 1984. Influenza virus-specific human cototoxic $T$ cell clones: heterogeneity in antigenic specificity and restriction by class II MHC products. Cell. Immunol. 88:193-206.

25. Yasukawa, M., and J. M. Zarling. 1984. Human cytotoxic T cell clones directed against herpes simplex virus-infected cells. 1. Lysis restricted by MHC class II MB and DR antigens. J. Immunol. 133:422-427.

26. Borysiewicz, L. K., S. Morris, J. D. Page, and J. G. P. Sissons. 1983. Human cytomegalovirus-specific cytotoxic T lymphocytes: requirements for in vitro generation and specificity. Eur. J. Immunol. 13:804-809.

27. Ndumbe, P. M., and R. J. Levinsky. 1986. Generation of phenotypically different $\mathrm{T}$ cell populations by cell-free or cell-bound preparations of varicella zoster virus. Immunol. Lett. 13:191-195.

28. Westaway, E. G. 1987. Flavivirus replication strategy. $A d v$. Virus Res. 33:45-90.

29. Zhao, B., E. Mackow, A. Buckler-White, L. Markoff, R. M. Chanock, C. J. Lai, and Y. Makino. 1986. Cloning full-length dengue 4 type 4 viral DNA sequences: Analysis of genes coding for structural proteins. Virology. 155:77-88.

30. Mackow, E., Y. Makino, B. Zhao, Y. M. Zhang, L. Markoff, A. Buckler-White, M. Guiler, R. Chanock, and C. J. Lai. 1987. The nucleotide sequence of dengue type 4 virus: analysis of genes coding for nonstructural proteins. Virology. 159:217-228.

31. Russell, P. K., W. E. Brandt, and J. M. Dalrymple. 1980. Chemical and antigenic structure of flaviviruses. In The Togaviruses: Biology, Structure, Replication. R. W. Schlesinger, editor. Academic Press, Inc., New York. 503-529.

32. Kaufman, B. M., P. L. Summers, D. R. Dubois, and K. C. Eckels. 1987. Monoclonal antibodies against dengue 2 virus E-glycoprotein protect mice against lethal dengue infection. Am. J. Trop. Med. Hyg. 36:427-434.

33. Schlesinger, J. J., M. W. Brandriss, and E. E. Walsh. 1987. Protection of mice against dengue 2 virus encephalitis by immunization with dengue 2 virus non-structural glycoprotein NS1. J. Gen. Virol. 68:853-857.

34. Burke, D. S., A. Nisalak, D. E. Johnson, and R. M. Scott. 1988. A prospective study of dengue infections in Bangkok. Am. J. Trop. Med. Hyg. 38:172-180. 
35. Kliks, S. C., S. Nimmanitya, A. Nisalak, and D. S. Burke. 1988. Evidence that maternal dengue antibodies are important in the development of dengue hemorrhagic fever in infants. Am. J. Trop. Med. Hyg. 38:411-419.

36. Cunningham, A. L., and T. C. Merigan. 1984. Leu-3+ T cells produce $\gamma$-interferon in patients with recurrent herpes labialis. J. Immunol. 132:197-202.

37. Yamada, Y. K., A. Meager, A. Yamada, and F. A. Ennis. 1986. Human interferon alpha and gamma production by lymphocytes during the generation of influenza virus-specific cytotoxic $\mathrm{T}$ lymphocytes. J. Gen. Virol. 67:2325-2334.

38. Friedman, R. M., and S. N. Vogel. 1983. Interferons with special emphasis on the immune system. Adv. Immunol. 34:97-140.
39. Trinchieri, G., and B. Perussia. 1985. Immune interferon: a pleiotropic lymphokine with multiple effects. Immunol. Today. 6:131-136.

40. Guyre, P. M., P. M. Morganelli, and P. Miller. 1983. Recombinant immune interferon increases immunoglobulin $G$ Fc receptors on cultured human mononuclear phagocytes. J. Clin. Invest. 72:393-397.

41. Perussia, B., E. T. Dayton, R. Lazarus, V. Fanning, and G. Trinchieri. 1983. Immune interferon induces the receptor for monomeric IgG1 on human monocytic and myeloid cells. J. Exp. Med. 158:1092-1113.

42. Halstead, S. B., E. J. O'Rourke, and A. C. Allison. 1977. Dengue viruses and mononuclear phagocytes. II. Identity of blood and tissue leukocytes supporting in vitro infection. J. Exp. Med. 146:218229. 